\title{
Community composition and species richness of parasitoids infesting Yponomeuta species in the Netherlands
}

\author{
Daniel F. R. Cleary \\ Institute for Biodiversity and Ecosystem Dynamics, University of Amsterdam, PO Box 94766, 1090 GT \\ Amsterdam, The Netherlands. Present address: National Museum of Natural History, 'Naturalis', \\ P.O. Box 9517, 2300 RA Leiden, The Netherlands, Email: cleary@naturalis.nnm.nl
}

Keywords: ANOSIM, beta diversity, community composition, distance, species richness

\begin{abstract}
Parasitoid assemblages infesting Yponomeuta species in the Netherlands were investigated. Parasitoid species richness and community composition were related to host species, habitat, temporal and spatial variation. Both community structure and species richness did not differ among habitats. There was no significant difference in species richness between years (1994 and 1995) but there was a significant difference in community composition. Community composition and species richness both differed among host species, although this latter result was solely due to the host species $Y$. evonymellus. There was no significant relationship between community similarity and distance. These results indicate that the parasitoids of the moth genus Yponomeuta in the Netherlands appear to form a spatially stable, but temporally variable community. Most of the variation in community structure was, however, related to the host species. The marked difference in parasitoid species richness and community composition of $Y$. evonymellus when compared to the other species warrants further study.
\end{abstract}

\section{Contents}

$\begin{array}{ll}\text { Introduction } & 255 \\ \text { Material and method } & 256 \\ \text { Sampling and localities } & 256 \\ \text { Analyses } & 258 \\ \text { Community composition } & 258 \\ \text { Species richness } & 258 \\ \text { Results } & 258 \\ \text { Community composition } & 258 \\ \text { Species richness } & 259 \\ \text { Discussion } & 259 \\ \text { References } & 260 \\ \text { Appendix I } & 261\end{array}$

\section{Introduction}

Both deterministic and stochastic processes are believed to be important in structuring patterns of community similarity in natural environments (Robinson et al. 2000). Recently, however, there has been considerable debate on the relative importance of these processes in explaining patterns of beta diversity (Bell, 2001; Condit et al., 2002; Duivenvoorden, 2002; Whitfield, 2002; Wright, 2002). In a study of small mammals, for example, in Australia, Williams et al. (2002) found that community composition was strongly related to vegetation structure. Likewise, urban bird species richness was found to be independent of the surrounding periurban landscape and city size in North America and Europe, and to primarily depend on local habitat structure (Clergeau et al., 2001). Distance played an important role in predicting patterns of plant community similarity in Central and South American lowland rainforests (Condit et al., 2002). On the other hand in a study of freshwater invertebrates in Israel neither distance nor environmental variables explained a significant amount of variation in levels of community similarity (Spencer et al. 2002).

The present study concerns the parasitoid community of the moth genus Yponomeuta in the Netherlands. Parasitoids are significant components of many communities. Assemblages of parasitoids, for example, can have important regulatory effects on their host species and have been shown to be able to control the population dynamics of their hosts 
by stabilizing otherwise chaotic growth and decline cycles (Driessen and Hemerik, 1991; but see Begon et al., 1995).

Parasitoid species, furthermore, appear to recognise their resources as a single niche axis. Each parasitoid species entering a community involves sequential divisions of resources. There appears to be a stepwise random division of resources at each addition of a species so that these communities are minimally structured, which implies that biotic processes such as competition and predation play a small role in the developent of parasitoid assemblages. The most important ecological factor for parasitoids is probably the stage of the host utilised so that by partitioning even a single host a potentially rich parasitoid community can develop (Naeem and Hawkins, 1994).

The focal parasitoid community used in this study is the guild of parasitoids infesting the moth genus Yponeomeuta. The importance of distance, habitat, and host species in structuring patterns of diversity in the parasitoids that feed on Yponomeuta moth species in the Netherlands is assessed. The relationship between distance and community similarity is assumed to be a predictor of communitywide dispersal rates (Spencer et al. 2002). All Yponomeuta hosts are univoltine and feed on various shrub and tree species, often becoming a pest when ornamental or crop species (e.g., apple or plum) are consumed. The Yponomeuta host species and their parasitoids are generally very common, conspicuous (they often spin large webs around shrubs or trees), easy to sample, and identify (Martouret et al., 1966).

The questions addressed with this study are: I

1. Is the community similarity of the parasitoids infesting Yponomeuta moths related to temporal variation (between years), habitat, and/or host species?

2. Is there a relationship between community similarity and distance?

3 . Is the species richness of the parasitoids infesting Yponomeuta moths related to temporal variation (between years), habitat, and/or host species?

\section{Material and method}

\section{Sampling and localities}

Sampling took place in the Netherlands in a wide variety of habitats ranging from urban parks to forests (Table 1). The Yponomeuta host species were often sympatric, and the webs left by feeding caterpillars were easily observed and sampled.

In order to estimate community similarity and species richness of parasitoid assemblages infesting Yponomeuta spp. populations of four host species, $Y$. cagnagellus, $Y$. evonymellus, $Y$. padellus and $Y$. rorellus were sampled in the Netherlands during 1994 and 1995. The sampling localities and geographic position in the Netherlands are listed in Table 1. All host-populations with less than ten parasitoid individuals and 100 host individuals were excluded from the analyses. Various sites and hostpopulations were sampled in each locality. During the collection, the habitat (dune scrub, rural hedgerow, forest and urban park) and plant species on which the host was found were noted. Each site was checked for all potential Yponomeuta hosts. In the analysis, each host species per site is considered a single sample. Yponomeuta larvae from each host population were raised indoors at the Institute for Biodiversity and Ecosystem Dynamics (Amsterdam). The larvae were bred in enclosed cages on the same food plant species upon which they were found. Caterpillars or pupae with parasitoids (these were easily distinguished from healthy caterpillars or pupae) were selected and placed in large tubes so that the emerging parasitoids could be collected.

The following parasitoid species were collected from Yponomeuta host populations: Ageniaspis fuscicollis (gregarious primary parasitoid of eggs), Diadegma armillata (solitary polyphagous primary parasitoid from third instar on), Herpestomes brunnicornis (solitary parasitoid from fifth instar on), Agria mamillata (polyphagous predator consuming fifth instar larvae and pupae), Mesochorous vittator (solitary secondary parasitoid of Diadegma armilllata), Tetrastichus evonymellae (gregarious primary and secondary parasitoid from third instar on), Agrypon anxium (solitary polyphagous primary parasitoid from third instar on), and Pimpla turio- 
Table 1. Host populations (Pop.), Sites, localities (within sites), year of sampling, host, and host plant (plant) of local parasitoid communities collected in the Netherlands. Hab: habitat type, Total: number of caterpillars collected from a population, \%par: percentage of caterpillars infected by a parasitoid, Rich: rarefied species richness $(n=10)$, Yp: number of host species present in a locality.

\begin{tabular}{|c|c|c|c|c|c|c|c|c|c|c|}
\hline Pop. & Site & ، Locality & Year & Host & Plant & $\mathrm{Hab}$ & Total & $\% \mathrm{Par}$ & Rich & Yp \\
\hline C94.1 & Awd duinen & Zuid & 1994 & Y. cag & E. europeaus & Dune & 1371 & 2.4 & 1.0 & 2 \\
\hline C94.100 I & Meijendel & Bierlap behind Uitkijk & 1994 & $Y . c a g$ & E. europeaus & Dune & 280 & 15.7 & 2.5 & 3 \\
\hline C94.17 E & Bergschenhoek & Lage Bergse Bos & 1994 & $Y . c a g$ & E. europeaus & Rural & 395 & 9.4 & 1.0 & 4 \\
\hline C94.3 & Awd duinen & Midden & 1994 & $Y . c a g$ & E. europeaus & Dune & 1710 & 2.8 & 1.0 & 2 \\
\hline C94.32 I & Malden & Heemtuin; rand achteraan & 1994 & Y.cag & E. europeaus & Forest & 262 & 18.3 & 1.6 & 4 \\
\hline C94.41 & Wageningen & Bornse steeg; beh. stud. Flat & 1994 & Y. cag & E. europeaus & Rural & 104 & 28.9 & 1.3 & 3 \\
\hline $\mathrm{C} 94.5$ & Awd duinen & Noord & 1994 & $Y . \operatorname{cag}$ & E. europeaus & Dune & 410 & 3.7 & 1.0 & 2 \\
\hline C94.84 I & Nieuwekerk & Parallelweg zuid & 1994 & Y. cag & E. europeaus & Rural & 317 & 13.6 & 1.0 & 2 \\
\hline $\mathrm{C} 95.27$ & Almelo & Schapendijk & 1995 & Y. cag & E. europeaus & Rural & 2099 & 21.0 & 1.0 & 2 \\
\hline C95.32 I & Maashees & Camping & 1995 & Y. cag & E. europeaus & Rural & 1215 & 10.1 & 1.1 & 2 \\
\hline C95.41 & Wageningen & Blauwe Bergen & 1995 & $Y . c a g$ & E. europeaus & Park & 402 & 17.4 & 1.4 & 3 \\
\hline C95.49 I & Bergschenhoek & Lage Bergse Bos & 1995 & $Y . \operatorname{cag}$ & E. europeaus & Rural & 1580 & 12.7 & 1.0 & 4 \\
\hline C95.53 I & Meijendel & Bierlap (behind) and Uitkijk & 1995 & Y. cag & E. europeaus & Dune & 516 & 6.6 & 1.3 & 3 \\
\hline $\mathrm{C} 95.80$ & Amsterdam & Rembrandtpark & 1995 & Y. cag & E. europeaus & Rural & 387 & 13.7 & 1.0 & 4 \\
\hline E94.107 & Amsterdam & Louwesweg & 1994 & Y. evo & P. padus & Rural & 1512 & 2.2 & 3.1 & 2 \\
\hline E94.34 I & Malden & Heemtuin; vennetje & 1994 & $Y$, evo & P. padus & Forest & 279 & 11.2 & 3.6 & 4 \\
\hline E94.47 & Wageningen & Bornse Steeg; road & 1994 & Y. evo & P. padus & Rural & 658 & 5.1 & 3.2 & 4 \\
\hline E94.49 & Oosthuizen & Oude sportveld & 1994 & Y. evo & $P$. padus & Rural & 234 & 7.3 & 2.0 & 3 \\
\hline E94.77 & Amsterdam & Rembrandtpark & 1994 & Y. evo & P. padus & Dune & 662 & 2.7 & 4.0 & 4 \\
\hline E94.79 & Rijnsaterwoude & Geluidswal N 207 & 1994 & Y. evo & P. padus & Rural & 397 & 6.9 & 3.5 & 2 \\
\hline E94.85 & s Gravendeel & Sportpark & 1994 & Y. evo & P. padus & Park & 155 & 20.6 & 1.0 & 1 \\
\hline E94.96 & Amsterdam & Anna's Hoeve & 1994 & Y. evo & P. padus & Rural & 2173 & 7.0 & 2.5 & 4 \\
\hline E94.98 & Meijendel & Uitkijk & 1994 & Y. evo & P. padus & Dune & 1817 & 1.0 & 4.5 & 3 \\
\hline E95.23 & Almelo & Wateregge & 1995 & Y. evo & $P$. padus & Rural & 305 & 6.2 & 1.0 & 1 \\
\hline E95.24 & Nieuwe ter Aa & Bosdijk & 1995 & Y. evo & P. padus & Rural & 1873 & 6.4 & 1.0 & 2 \\
\hline E95.38 & Malden & Heemtuin; vennetje & 1995 & Y. evo & P. padus & Forest & 511 & 2.0 & 3.0 & 4 \\
\hline E95.45 & Almelo & Bosrand & 1995 & Y. evo & P. padus & Forest & 7526 & 4.6 & 2.5 & 1 \\
\hline E95.47 & Bergschenhoek & Lage Bergse Bos & 1995 & Y. evo & P. padus & Rural & 3216 & 0.9 & 1.9 & 4 \\
\hline E95.51 & Meijendel & Uitkijk & 1995 & Y. evo & P. padus & Dune & 4002 & 0.7 & 1.0 & 3 \\
\hline E95.60 & Amsterdam & Rembrandtpark & 1995 & Y. evo & P. padus & Park & 2723 & 1.7 & 1.0 & 4 \\
\hline E95.74 & Hoge Veluwe & Kemperberg; in de bocht & 1995 & Y. evo & P. padus & Forest & 286 & 14.6 & 4.1 & 2 \\
\hline PA94.64 & Hoge Veluwe & Heidebloem; $7+8$ 'eetplaats' & 1994 & Y. pad & A. lamarckii & Forest & 124 & 28.2 & 1.0 & 2 \\
\hline PA95.67 & Hoge Veluwe & Heidebloem ' 6 ', Zandweg & 1995 & Y. pad & A. lamarckii & Forest & 109 & 19.2 & 2.5 & 2 \\
\hline PB95.84 & Malden & Zeefvliegveld B & 1995 & Y. pad & S. aucuparia & Forest & 129 & 10.9 & 1.0 & 4 \\
\hline PC94.103 & Rottebandreef & Rottebaandreef, Molenlaan & 1994 & $Y . p a d$ & C. mongyna & Rural & 193 & 10.9 & 1.0 & 3 \\
\hline PC94.4 & Awd duinen & Midden & 1994 & Y. pad & C. mongyna & Dune & 144 & 13.9 & 1.0 & 2 \\
\hline PC94.67 & Hoge Veluwe & Kemperberg ' 10 ' & 1994 & $Y \cdot p a d$ & C. mongyna & Forest & 100 & 15.0 & 1.0 & 2 \\
\hline PC94.80 & Rijnsaterwoude & Geluidswal N 207 & 1994 & Y. pad & C. mongyna & Rural & 176 & 10.2 & 1.9 & 2 \\
\hline PC95.28 & Almelo & Schapendijk & 1995 & Y. pad & C. mongyna & Rural & 557 & 24.8 & 1.1 & 2 \\
\hline PC95.36 & Malden & Heemtuin; rand vooraan & 1995 & Y. pad & C. mongyna & Forest & 311 & 26.7 & 1.0 & 4 \\
\hline PC95.48 & Bergschenhoek & Lage Bergse Bos & 1995 & $Y . p a d$ & C. mongyna & Rural & 818 & 21.8 & 1.0 & 4 \\
\hline PC95.52 & Meijendel & Bierlap (behind, Uitkijk & 1995 & Y. pad & C. mongyna & Dune & 840 & 3.6 & 1.0 & 3 \\
\hline PC95.75 & Amsterdam & Rembrandtpark & 1995 & Y. pad & C. mongyna & Park & 766 & 4.3 & 1.0 & 4 \\
\hline PS94.83 & Nieuwekerk & Parallelweg zuid & 1994 & Y. pad & P. spinosa & Rural & 408 & 32.5 & 1.2 & 2 \\
\hline PS95.33 & Maashees & camping & 1995 & Y. pad & P. spinosa & Rural & 147 & 21.1 & 1.0 & 2 \\
\hline PS95.37 & Malden & Heemtuin; rand vooraan & 1995 & Y.pad & P. spinosa & Forest & 174 & 8.6 & 1.0 & 4 \\
\hline R94.18 & Bergschenhoek & Lage Bergse Bos & 1994 & Y. ror & Salix sp. & Rural & 115 & 30.4 & 1.0 & 4 \\
\hline R94.76 & Amsterdam & Rembrandtpark & 1994 & Y. ror & Salix sp. & Park & 381 & 6.8 & 2.0 & 4 \\
\hline R95.50 & Bergschenhoek & Lage Bergse Bos & 1995 & Y. ror & Salix sp. & Rural & 208 & 35.1 & 1.0 & 4 \\
\hline R95.50 & Bergschenhoek & Lage Bergse Bos & 1995 & "Y.ror & Salix sp. & Rural & 117 & 13.5 & 1.2 & 4 \\
\hline $\mathrm{R} 95.83$ & Amsterdam & Rembrandtpark & 1995 & Y. ror & Salix sp. & Park & 1611 & 6.7 & 1.0 & 4 \\
\hline
\end{tabular}


nellae (solitary primary parasitoid of pupae). More detailed descriptions of the parasitoid species can be found in Dijkerman et al. (1986).

\section{Analyses}

\section{Community composition}

Variation in the overall community composition among habitats (dune scrub, rural hedgerow, forest and urban park), among host species, and between years (1994 and 1995) was tested for significance using ANOSIM (non parametric analysis of similarities) with the package PRIMER (Clarke and Gorley 2001). ANOSIM is roughly analogous to standard univariate ANOVAs, and tests the variance within and between a priori defined groups in ordinate space. A Bray-Curtis similarity matrix was used for across-site comparisons. The ANOSIM R statistic values are an absolute measure of how separated the groups are. A zero $(0)$ indicates that there is no difference among groups, while a one (1) indicates that all samples within groups are more similar to one another than any samples from different groups (Clarke and Gorley, 2001). The results of the ANOSIM are presented in addition to a multidimensional scaling ordination based on the same similarity matrix. Three one-way ANOSIMs were used where I tested for significant differences among habitat type, host type, and between years (for details and description of ANOSIM see Clarke and Gorley, 2001). The relationship between community similarity and distance was tested with the RELATE option of PRIMER, which tested for a significant relationship between two matrices of which one was a matrix of community similarity based on the Bray-Curtis similarity matrix and the other was a matrix of distances between pairs of host-populations. The distances were based on Universal Transverse Mercator (UTM) coordinates from each site.

\section{Species richness}

Rarefaction analysis was conducted, due to differing sampling sizes per locality, with the DIVERSE option of the PRIMER program (Clarke and Gorley, 2001). The sample size used for rarefaction of parasitoids per host population was 10 individuals. Species richness among habitat types, hosts, and years was tested with a Kruskal Wallis test using Statistica for Windows (Statistica for Windows, 1996)

\section{Results}

\section{Community composition}

There was no significant difference in community composition among local parasitoid communities from different habitats $\left(R_{\text {ANOSIM }}=-0.038, P=0.282\right)$, but there was a significant difference between years $\left(R_{\text {ANOSIM }}=0.07, P=0.012\right)$ and among local parasitoid communities from different host species $\left(\mathrm{R}_{\text {ANOSIM }}=0.126, \mathrm{P}=0.002\right)$. Pairwise comparisons showed that there was no significant difference among local parasitoid communities of $Y$. cagnagellus, $Y$. padellus, and $Y$. rorellus, (cag-pad: $\mathrm{R}_{\text {ANOSIM }}=0.003, \mathrm{p}=0.370$; cag-ror: $\mathrm{R}_{\text {ANOSIM }}=$ $-0.092, p=0.692$; pad-ror: $R_{\text {ANOSIM }}=-0.095, p=$ 0.647 ) but local communities of $Y$. evonymellus differed significantly from the three other hosts (Figure 1; evo-cag: $\mathrm{R}_{\text {ANOSIM }}=0.331, \mathrm{p}<0.001$; evopad: $R_{\text {ANOSIM }}=0.274, p<0.001$; evo-ror: $R_{\text {ANOSIM }}=$ $0.164, p=0.062$ ). There was no significant relationship between community similarity and distance

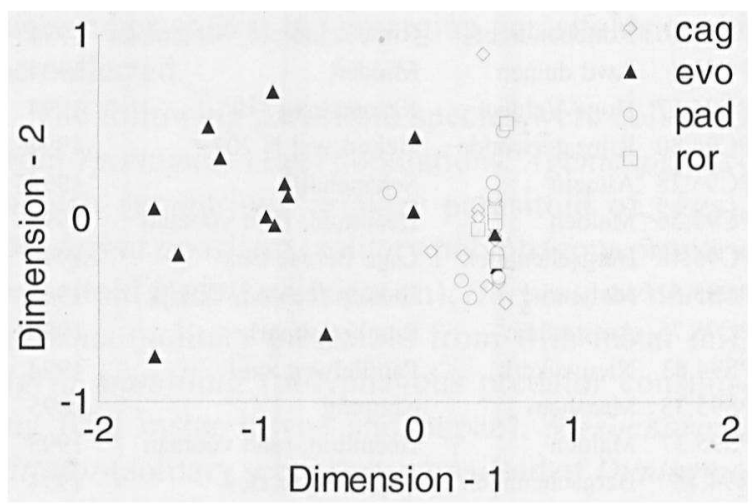

Fig. I. Multidimensional scaling ordination based on the parasitoids of the Yponomeuta species complex in the Netherlands. cag: Y. cagnagellus, evo: Y. evonymellus, pad: Y. padellus, ror: $Y$. rorellus. The first two dimensions of the analysis are shown. 
Table 2. Summary of statistics of species richness grouped by host species, year, and habitat.

\begin{tabular}{llllllll}
\hline Factor & Variable & Median & Minimum & Maximum & $\begin{array}{l}\text { Lower } \\
\text { quartile }\end{array}$ & $\begin{array}{l}\text { Upper } \\
\text { quartile }\end{array}$ & $\begin{array}{l}\text { Quartile } \\
\text { range }\end{array}$ \\
\hline Host species & Y. cagnagellus & 1.00 & 1.00 & 2.54 & 1.00 & 1.33 & 0.33 \\
& Y. evonymellus & 2.49 & 1.00 & 4.46 & 1.00 & 3.53 & 2.53 \\
& Y. padellus & 1.00 & 1.00 & 2.48 & 1.00 & 1.07 & 0.07 \\
Year & Y. rorellus & 1.00 & 1.00 & 1.98 & 1.00 & 1.24 & 0.24 \\
& 1994 & 1.33 & 1.00 & 4.46 & 1.00 & 2.54 & 1.54 \\
Habitat & 1995 & 1.00 & 1.00 & 4.06 & 1.00 & 1.29 & 0.29 \\
& Dune & 1.00 & 1.00 & 4.46 & 1.00 & 2.54 & 1.54 \\
& Rural & 1.04 & 1.00 & .3 .53 & 1.00 & 1.93 & 0.93 \\
& Forest & 1.62 & 1.00 & 4.06 & 1.00 & 3.00 & 2.00 \\
\hline
\end{tabular}

(Rho $=0.007, p=0.394)$. The parasitoid species and populations sampled during this study and their abundance in each site is presented in Appendix I.

\section{Species richness}

There was no significant difference in species richness of local parasitoid communities among habitat types (Kruskal Wallis Test: $\mathrm{H}=1.584, \mathrm{p}=0.663$ ) or between years (Kruskal Wallis Test: $\mathrm{H}=3.155$, $\mathrm{p}=0.076)$, but there was a significant difference among hosts (Table 2; Kruskal Wallis Test: $\mathrm{H}=$ 13.236, $\mathrm{p}=0.005)$. The parasite guild infesting $Y$. evonymellus was significantly richer that the guilds infesting the other host species.

\section{Discussion}

The community composition of the parasitoids infesting Yponomeuta spp. did not differ significantly between very different habitats (e.g. city parks versus dune scrub) and there was no significant relationship between community structure and distance. Community composition did, however, differ marginally between years, but the main difference in community composition was between host species. Importantly, in both community composition and species richness there were no significant differences among populations from the host species $Y$ : cagnagellus, $Y$. padellus, and $Y$. rorellus, but popu- lations from $Y$. evonymellus deviated significantly from all of the other host species.

Taking only the three host species $Y$. cagnagellus, $Y$. padellus, and $Y$. rorellus into account this indicates that the parasitoid assemblages of these species are locally impoverished (generally only a single parasitoid species present) and spatially homogenous indicating that there is no dispersal limitation of these parasitoids in the Netherlands. Despite the fact that the Yponomeuta species here share no food plants they may (because of the overlap in eclosion; Martouret et al., 1966) engage in apparent competition (Holt and Lawton, 1993; Thomas et al., 1997) through their shared parasitoids.

The difference in community composition and species richness between $Y$. evonymellus and the other species may be related to the ability of this species to suppress levels of infestation by the specialist parasitoid Ageniaspis fuscicollis. Dijkerman (1987) showed that the level of infestation of A. fuscicollis was much lower in $Y$. evonymellus than in the other Yponomeuta host species. The exact mechanism of this suppression is unknown but may involve some sort of encapsulation of the eggs of A. fuscicollis. Apparently the ability of $Y$. evonymellus to reduce levels of parasitation by A. fiscicollis has created opportunities for the other generalist parasitoids to thrive and locally coexist in this host species. 


\section{References}

Begon M, Sait SM, Thompson DJ 1995. Persistence of a parasitoid-host system-refuges and generation cycles. Proceedings of the Royal Society London B. 260: 131-137.

Bell G. 2001. Neutral macroecology. Science 293: 24132418.

Clarke K R, Gorley R N 2001. Primer v5: user manual/ tutorial. - Primer-E Ltd. Plymouth.

Clergeau P, Jokimäki J, Savard J.-P. L. 2001. Are urban bird communities influenced by the bird diversity of adjacent landscapes? Journal of Applied Ecology 38: 11221134.

Condit R, Pitman N, Leigh EG, Chave J, Terborgh J, Foster RB, Nunez P, Aguilar S, Valencia R, Villa G, Muller-Landau H. C, Losos E, Hubbell SP. 2002. Betadiversity in tropical forest trees. Science 295: 666-669.

Dijkerman, HJ. 1987. Parasitoid complexes and patterns of parasitization in the genus Yponomeuta Latreille (Lepidoptera, Yponomeutidae). Journal of Applied Entomology 104: 390-402.

Dijkerman, HJ, de Groot, JMB, Herrebout, WM. 1986. The parasitoids of the genus Yponomeuta Latreille (Lepidoptera, Yponomeutidae) in the Netherlands. Proceedings van de Koninklijke Nederlandse Akademie van Wetenschappen C 89: 379-398.

Driessen G, Hemerik L. 1991. Aggregative responses of parasitoids and parasitism in populations of Drosophila breeding in fungi. Oikos 61: 96-107.

Duivenvoorden JF, Svenning J-C, Wright SJ. 2002. Beta diversity in tropical forests. Science 295: 636-637.

Holt, RD, Lawton, JH. 1993. Apparent competition and enemy-free space in insect host-parasitoid communities. American Naturalist 142: 623-645
Martouret D, Réal P, Arambourg Y, Balachowsky AS. 1966. Famille des Hyponomeutidae. In: Entomologie Appliquée à l'Agriculture traité publié sous la direction de A.S. Bakchovsky. Messon et Cie éditeurs. Vol II Lepidoptères: 99-175.

Naeem S, Hawkins BA. 1994. Minimal community structure: how parasitoids divide resources. Ecology 75: 7985.

Robinson WD, Brawn JD, Robinson SK. 2000. Forest bird community structure in central Panama: influence of spatial scale and biogeography. Ecological Monographs 70: 209-235.

Spencer M, Schwartz SS, Blaustein L. 2002. Are there fine-scale patterns in community similarity among temporary freshwater pools? Global Ecology and Biogeography 11: 71-78.

Statistica for Windows 1996. Version 5.0. Statsoft Inc. Tulsa, OK, USA.

'Thomas JA, EImes GW, Clarke RT, Kim KG, Munguira ML, Hochberg ME. 1997. Field evidence and model predictions of butterfly-mediated apparent competition between gentian plants and red ants. Acta Oecologica 18: 671-684.

Whitfield J. 2002. Neutrality versus the niche. Nature 417: 480-481.

Williams SE, Marsh H, Winter J. 2002. Spatial scale, species diversity, and habitat structure: small mammals in Australian tropical rain forest. Ecology 83: 1317-1329.

Wright SJ. 2002. Plant diversity in tropical forests: a review of mechanisms of species coexistence. Oecologia 130: $1-14$.

Received: 25 February 2002

Accepted: 24 September 2004 
Appendix I. Number of parasitoids, grouped by species, collected per host population. Populations (Pop.) are same as in Table 1 .

\begin{tabular}{|c|c|c|c|c|c|c|c|c|}
\hline Pop. & $\begin{array}{l}\text { Ageniaspis } \\
\text { fuscicollis }\end{array}$ & $\begin{array}{l}\text { Diadegma } \\
\text { armillata }\end{array}$ & $\begin{array}{l}\text { Herpestomes } \\
\text { brunnicornis }\end{array}$ & $\begin{array}{l}\text { Agria } \\
\text { mamillata }\end{array}$ & $\begin{array}{l}\text { Mesochorous } \\
\text { vittator }\end{array}$ & $\begin{array}{l}\text { Tetrastichus } \\
\text { evonymellae }\end{array}$ & $\begin{array}{l}\text { Agrypon } \\
\text { anxium }\end{array}$ & $\begin{array}{l}\text { Pimpla } \\
\text { turionellae }\end{array}$ \\
\hline C94.1 & 33 & $\vdots 0$ & 0 & 0 & 0 & 0 & 0 & 0 \\
\hline C94.100 & $16^{\prime \prime}$ & 0 & 3 & 25 & 0 & 0 & 0 & 0 \\
\hline C94.17 & 37 & 0 & 0 & 0 & 0 & 0 & 0 & 0 \\
\hline C94.3 & 48 & 0 & 0 & 0 & 0 & 0 & 0 & 0 \\
\hline C94.32 & 44 & 0 & 0 & 4 & 0 & 0 & 0 & 0 \\
\hline C94.41 & 29 & 0 & 0 & 1 & 0 & 0 & 0 & 0 \\
\hline C94.5 & 15 & 0 & 0 & 0 & 0 & 0 & 0 & 0 \\
\hline C94.84 & 43 & 0 & 0 & 0 & 0 & 0 & 0 & 0 \\
\hline C95.27 & 441 & 0 & 0 & 0. & 0 & 0 & 0 & 0 \\
\hline C95.32 & 122 & 0 & 0 & 0 & 0 & 0 & 1 & 0 \\
\hline C95.41 & 67 & 3 & 0 & 0 & 0 & 0 & 0 & 0 \\
\hline C95.49 & 200 & 0 & 0 & 0 & 0 & 0 & 0 & 0 \\
\hline C95.53 & 33 & 0 & 0 & 1 & 0 & 0 & 0 & 0 \\
\hline C95.80 & 53 & 0 & 0 & 0 & 0 & 0 & 0 & 0 \\
\hline E94.107 & 7 & 21 & 0 & 0 & 2 & 3 & 0 & 0 \\
\hline E94.34 & 6 & 18 & 0 & 1 & 4 & 2 & 0 & 0 \\
\hline E94.47 & 9 & 19 & 0 & 0 & 3 & 0 & 2 & 0 \\
\hline E94.49 & 0 & 13 & 0 & 0 & 4 & 0 & 0 & 0 \\
\hline E94.77 & 6 & 7 & 0 & 0 & 2 & 1 & 1 & 0 \\
\hline E94.79 & 3 & 11 & 0 & 0 & 10 & 0 & 3 & 0 \\
\hline E94.85 & 0 & 32 & 0 & 0 & 0 & 0 & 0 & 0 \\
\hline E94.96 & 8 & 106 & 2 & 0 & $3 j$ & 0 & 0 & 0 \\
\hline E94.98 & 1 & 9 & 0 & 4 & 1 & 2 & 0 & 1 \\
\hline E95.23 & 19 & 0 & 0 & 0 & 0 & 0 & 0 & 0 \\
\hline E95.24 & 120 & 0 & 0 & 0 & 0 & 0 & 0 & 0 \\
\hline E95.38 & 8 & 1 & 0 & 1 & 0 & 0 & 0 & 0 \\
\hline E95.45 & 234 & 90 & 0 & 0 & 1 & 21 & 0 & 0 \\
\hline E95.47 & 26 & 2 & 0 & 0 & 1 & 0 & 0 & 0 \\
\hline E95.51 & 28 & 0 & 0 & 0 & 0 & 0 & 0 & 0 \\
\hline E95.60 & 46 & 0 & 0 & 0 & 0 & 0 & 0 & 0 \\
\hline E95.74 & 3 & 6 & 0 & 0 & 4 & 15 & 14 & 0 \\
\hline PA94.64 & 35 & 0 & 0 & 0 & 0 & 0 & 0 & 0 \\
\hline PA95.67 & 17 & 2 & 0 & 0 & 2 & 0 & 0 & 0 \\
\hline PB95.84 & 0 & 0 & 0 & 0 & 0 & 0 & 0 & 14 \\
\hline PC94.103 & 21 & 0 & 0 & 0 & 0 & 0 & 0 & 0 \\
\hline PC94.4 & 20 & 0 & 0 & 0 & $\therefore$ & 0 & 0 & 0 \\
\hline РС 94.67 & 15 & 0 & 0 & 0 & 0 & 0 & 0 & 0 \\
\hline PC 94.80 & 15 & 0 & 3 & 0 & 0 & 0 & 0 & 0 \\
\hline PC 95.28 & 137 & 1 & 0 & 0 & 0 & 0 & 0 & 0 \\
\hline PC95.36 & 83 & 0 & 0 & 0 & 0 & 0 & 0 & 0 \\
\hline PC 95.48 & 178 & 0 & 0 & 0 & 0 & 0 & 0 & 0 \\
\hline PC95.52 & 30 & 0 & 0 & 0 & 0 & 0 & 0 & 0 \\
\hline PC 95.75 & 33 & 0 & 0 & 0 & 0 & 0 & 0 & 0 \\
\hline PS94.83 & 131 & 0 & 0 & 1 & 0 & 1 & 0 & 0 \\
\hline PS95.33 & 31 & 0 & 0 & 0 & 0 & 0 & 0 & 0 \\
\hline PS95.37 & 15 & 0 & 0 & 0 & 0 & 0 & 0 & 0 \\
\hline R94.18 & 35 & 0 & 0 & 0 & 0 & 0 & 0 & 0 \\
\hline R94.76 & 19 & 0 & 7 & 0 & 0 & 0 & 0 & 0 \\
\hline R95.50a & 28 & $\theta$ & 0 & 0 & 0 & 0 & 0 & 0 \\
\hline R95.50b & 40 & 0 & 0 & 1 & 0 & 0 & 0 & 0 \\
\hline R95.83 & 108 & 0 & 0 & 0 & 0 & 0 & 0 & 0 \\
\hline
\end{tabular}

